\title{
State of the art on modeling and optimization of Smart electricity networks
}

\author{
Hamza Wertani \\ Research Laboratory Smart \\ Electricity \\ \& ICT, SE\&ICT Lab., LR18ES44. \\ National Engineering school of \\ Carthage, University of Carthage \\ Tunisia \\ hamzawertani22@gmail.com
}

\author{
Jamel Ben Salem \\ Research Laboratory Smart \\ Electricity \\ \& ICT, SE\&ICT Lab., LR18ES44. \\ National Engineering school of \\ Carthage, University of Carthage \\ Tunisia \\ bsj_jamel@yahoo.fr
}

\author{
Mohamed Najeh Lakhoua \\ Research Laboratory Smart \\ Electricity \\ \& ICT, SE\&ICT Lab., LR18ES44. \\ National Engineering school of \\ Carthage, University of Carthage \\ Tunisia \\ MohamedNajeh.Lakhoua@enicartha \\ ge.rnu.tn
}

\begin{abstract}
The increase in population and industrialization has increased the consumption of electricity. Currently, it is impossible to live without electricity. Indeed, it is necessary for the economic, social and industrial progress in all the countries of the world. This is why we are always asked to develop all types of energy to produce clean and safe to improve energy efficiency. Indeed, the use of new renewable energy sources helps to mitigate greenhouse gas emissions and dependence on centralized energy sickles. The difficulties of renewable energybased power systems lie in their production, which is not controllable and may not meet the increase in energy demand.
\end{abstract}

Keywords-Smart grid; photovoltaic systems; solar energy; production; consumption.

\section{INTRODUCTION}

Today, the electricity grid works in a unidirectional direction since the consumer uses as much electricity as he wants and when he wants and the producers manage to supply this quantity every second which poses important problems. This mode of operation is no longer possible, because of the large numbers of electronic devices used and the rise of renewable energies [1], [2]. For this reason, a new product was born to adapt to all our needs called the intelligent electric network "Smart Grid".

The intelligent electrical network makes it possible to modify the unidirectional direction of the electrical network by a bidirectional direction since the consumer takes part in the production of electricity "prosumers". What makes it possible to pass from a centralized generation towards a decentralized generation by the creation of the renewable power stations, to integrate new mechanisms, products and services, to supply electricity in the continuous mode without interruption, to improve the technology of, communication and information [3], [4].

The intelligence of the electricity network offers added value to customers for obtaining all the necessary information on their electronic uses, the quantity of electricity consumed and the quantity of electricity produced, as well as information on prices and the possibility of connecting with control centers to detect faults more quickly and resolve problems safely and quickly. Both to energy infrastructure and to the various levels of the network (production, network equipment, consumption, monitoring and control devices) to make it more durable, solid, reliable and efficient.

The smart grid is a very advanced technology, its main purpose is to balance the supply and demand of electricity at all times. Despite all disturbances whatever natural or human, the REI improves the reliability, stability, security and efficiency of energy distribution based on modern digital communication and control techniques, to provide a secure, sustainable and competitive supply to consumers, to take into account the actions of all stakeholders, to ensure the availability of information and control options in real time for consumers, to ensure automatic control of electricity throughout the electricity cycle and all the electronic devices used [5], [6].

\section{DEFINITIONS OF SMART GRID}

The concept of Smart Grid unites a number of technologies, consumer solutions and addresses several policy and regulatory drivers. Smart Grid does not have any single obvious definition. Definition of Smart Grid by European technology platform is,

"A Smart Grid is an electricity network that can intelligently integrate the actions of all users connected to itgenerators, consumers and those that do both-in order to efficiently deliver sustainable, economic and secure electricity supplies."

In smarter grids the Smart Grid is defined as: "A Smart Grid uses sensing, embedded processing and digital communications to enable the electricity grid to be observable (able to be measured and visualized), controllable (able to manipulated and optimized), automated (able to adapt and selfheal), fully integrated (fully interoperable with existing systems and with the capacity to incorporate a diverse set of energy sources)".

Definition of Smart Grid by U.S. department of energy is: "A Smart Grid uses digital technology to improve reliability, security and efficiency (both economic and energy) of the electrical system from large generation, through the delivery systems to electricity consumers and a growing number of distributed generation and storage resources".

IEC definition for Smart Grid is: "The Smart Grid is a developing network of transmission lines, equipment, controls and new technologies working together to respond immediately to our 21st Century demand for electricity".

IEEE definition for Smart Grid is: "The smart grid is a revolutionary undertaking-entailing new communicationsand control capabilities, energy source, generation models and adherence to cross jurisdictional regulatory structures".

\section{NEED FOR SMART GRID}

The Smart Grid is an advanced digital two-way power flow power system capable of self- healing, adaptive, resilient and sustainable with foresight for prediction under different uncertainties [7]. It is equipped for interoperability with present and future standards of components, devices and systems that are cyber-secured against malicious attack: 
(1) Opportunities to take advantage of improvements in electronic communication technology to resolve the limitations and costs of the electrical grid have become apparent.

(2) Concerns over environmental damage from fossilfired power stations.

(3) The rapidly falling costs of renewable based sources point to a major change from the centralized grid topology to one that is highly distributed.

Introducing Smart Grid to the electrical power utility grid infrastructure will,

(1) Improves the reliability of utility grid by reducing power quality disturbances and reducing consequences and probability of widespread blackouts.

(2) Allows for the advancements and efficiencies yet to be envisioned.

(3) Reduces electricity prices paid by consumers by exerting downward pressure.

(4) Better affordability is maintained for energy consumers.

(5) Greater choice of supply and information is provided to consumer.

(6) Integrates renewable/nonconventional DERs.

(7) Improves security by reducing the consequences and probability of natural disasters and manmade attacks. (8) Facilitate higher penetration of alternating power generation sources.

(9) Reduces loss of life and injuries from utility grid related events, thereby reduces safety issues.

(10) Integrates electrical vehicles as generating and storing devices, thereby revolutionize the transportation sector.

(11) Improves the overall efficiency by reducing loses and wastage of energy.

(12) Smart Grid reduces environmental pollution by reducing emission of greenhouse gases and carbon particulates and provides cleaner power by promoting deployment of more renewable DERs.

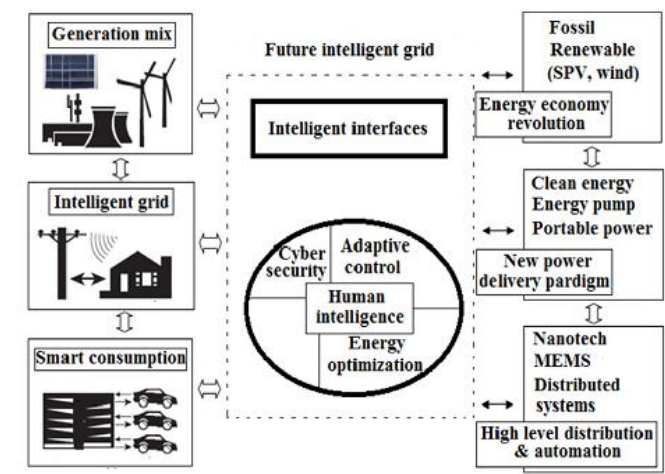

Fig.1. The intelligent grid.

\section{OPERATIONS FOR SMART GRID}

In the broadest sense, a smart grid combines electrical infrastructure with digital technologies that analyze and transmit the information received. These technologies are used at all levels of the network: production, transport, distribution and consumption [8].
Real-time flow control: sensors installed throughout the network instantly indicate electrical flows and consumption levels. Network operators can then redirect energy flows according to demand and send price signals to individuals to adapt their consumption (voluntarily or automatically).

Network interoperability: the entire electricity network includes the transmission network and the distribution network. The first connects the electricity production sites to the consumption zones: these are the main axes that crisscross the territory. The distribution network is similar to the secondary axes. It routes electricity to final consumers. Through the instantaneous exchange of information, smart grids promote interoperability between the managers of the transport network and those of the distribution network.

Integration of renewable energies into the grid: smart grids are based on an information system which makes it possible to predict the level of production and consumption in the short and long term. Renewable energies which often operate intermittently and in an unpredictable way (e.g. wind) can thus be better managed.

More responsible management of individual consumption: smart meters (or advanced meters for electricity) are the first application versions of the smart grid. Installed by consumers, they provide information on prices, peak consumption hours, quality and level of electricity consumption in the home. Consumers can then regulate their consumption themselves during the day. Network operators, on the other hand, can detect faults more quickly [9].

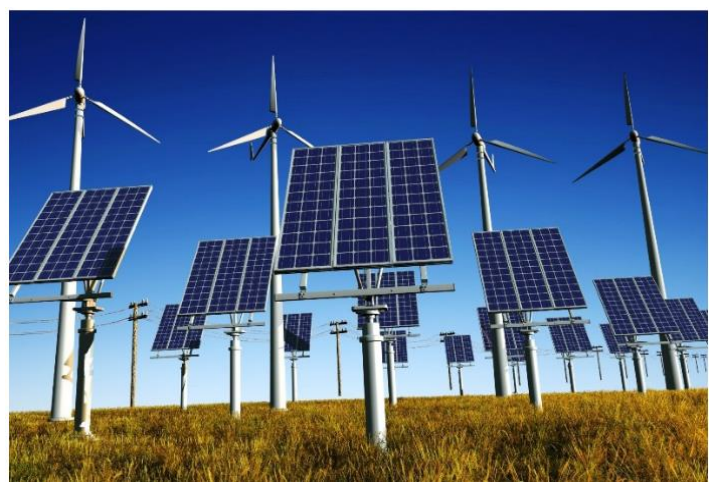

Fig.2. Photovoltaic and wind.

\section{EVOLUTION OF SMART GRID}

To face these new constraints, the current network must necessarily adapt, by integrating new information and communication technologies in order to maintain the balance between supply and demand. The electrical system goes from a situation where production is largely controllable, while consumption is less, to a situation where production will only be controllable to a certain extent and where consumption will be managed actively [10].

The smart grid will integrate renewable energies and educate producer, distributor and consumer on energy use. To manage these new needs and these new productions, smart electricity grids have two characteristics:

- They are communicating and interactive;

- They allow data to be exchanged between the various players in the electrical system to know, control, manage the network and they take into account the actions of all the stakeholders in the electrical system. 


\section{SMART GRID ARCHITECTURE: TOWARDS FLEXIBLE AND COMMUNICATING ELECTRICAL NETWORKS}

To cope with the changes in the energy context, electricity network managers can no longer rely solely on the forecast management of the electricity network (not very reactive to the intermittency of renewable energies for example), nor consider resizing the network (expensive and not optimal) [11].

The solution lies in the automation of the conduct of electrical networks, through the acquisition and exploitation in real time of information on the state of the networks. This involves the deployment of a computer network at the level of electrical infrastructure, and the implementation in the Information System (IS) of tools to operate it.

Thus equipped, electrical networks are like a spider's web where the meshes constantly interact via communication links. These meshes correspond to the actors of the electrical system: consumers, producers or both at the same time. In addition to electricity, these players produce and consume information in real time, thanks to the software modules with which they are equipped and various telecommunications means, such as mobile networks or Line Carrier Current (PLC). This permanent and instantaneous sharing of information between equipment preserves the stability of the electrical system while increasing its energy efficiency.

To illustrate the possibilities offered by ICT, take the example of the peak consumption at the end of the day on a weekday. Thanks to ICT, it becomes possible to act on demand rather than on supply. The electrical distributor, relying on remote control points and smart meters installed at customers' premises to send and receive information and instructions, can then send "erasure" requests to consumers through price incentives. The erasure can take, for example, the form of a cut in the heating for $15 \mathrm{~min}$ to $30 \mathrm{~min}$ of a home or a well insulated office. Without affecting consumer comfort, these erasure requests help smooth the load curve during peak hours while avoiding the need to mobilize production plants [12].

Born from the convergence of electrical networks and ICTs, Smart Grids thus consist of three layers which we find in Figure 3:

1. The first level corresponds to the infrastructure and electrical equipment carrying electricity, such as lines and transformers;

2. The second level corresponds to the communication infrastructure composed of different telecommunication technologies such as fiber optics, PLC, or the Third Generation (3G);

3. The third level corresponds to the computer applications which embody the "intelligence" of the network. Using information delivered in real time, these applications calculate instructions to send the equipment concerned and thus automate the operation of the electrical system. This intelligence is centralized at the network control centers or distributed on electrical equipment.

\section{ALIGNING THE INFORMATION SYSTEM WITH SMART GRID ORIENTED STRATEGY}

By processing the data sent in real time by the sensors installed on the electrical equipment and to consumers, the IS calculates instructions intended for remote-controlled bodies thus making it possible to control the electrical networks remotely. This automation of network management is a solution to quickly adapt them to the constraints introduced by the integration of renewable energies and new uses [13].

IS is therefore at the heart of the challenges of Smart Grids. The implementation of Smart Grids thus goes hand in hand with the upgrading of the IS of the managers of the electricity network. Indeed, this IS must fully integrate the evaluations brought about by Smart Grids in terms of the network manager's business processes, the actors affected, the information exchanged as well as the IT applications and underlying technical infrastructures [14], [15]..

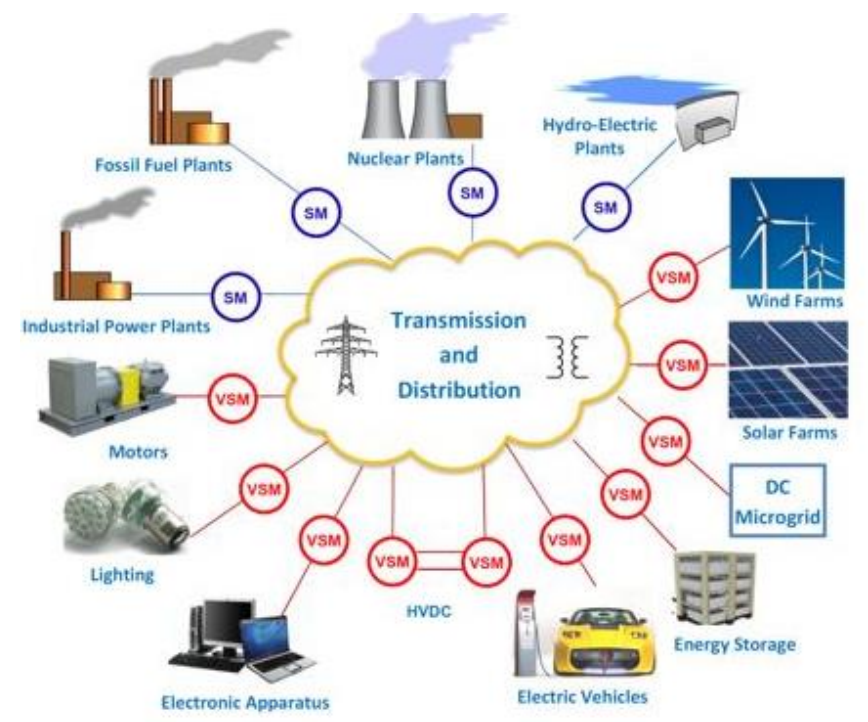

Fig.3. Architecture of smart grids.

Among these developments, we cite:

- New information flows from the electricity network;

- The entry into play of new players such as decentralized producers (wind, photovoltaic);

- New communicating equipment such as the link meter (Electricity Distribution Network France (ERDF) announces the deployment of 30 million meters;

- New European regulations and directives (in the case of European network operators);

- New uses, such as electric vehicles or connected homes.

In addition to their IS, power system operators must evolve their development strategies by considering new business models and new partners, while taking into account the emergence of new technologies and the requirements of legislators. An American study, conducted by IBM, CISCO, EPRI and South Carolina Edison, identifies five key strategic themes for the implementation of Smart Grids:

- Enable consumers to control their energy consumption and reduce their carbon footprint by using intelligent equipment and electric vehicles and by producing renewable energy at home;

- Improve employee safety and productivity by, for example, providing them with powerful tools for remote control, protective equipment, and mobile applications;

- Integrate renewable energy sources distributed on the network while ensuring the protection of electrical equipment, energy storage and network stability; •

Improve network efficiency and resilience through real-time measurement systems, analysis and remote control ; 
- Provide the necessary information and connectivity by developing an ICT infrastructure to meet the computing needs of the electricity network.

This last point is a sine qua non condition for the realization of the previous four. Given these key themes, network managers are considering strategies involving the adoption of Smart Grid technologies. The effective implementation of these strategies requires the automation of network actions and data processing, which therefore results in the deployment of new IS. In order to understand these emerging paradigms, business scenarios are developed, but it is essential to test and validate them before considering their final implementation [16].

Several physical demonstrators have been deployed. These pilot projects make it possible to carry out experiments in real conditions to test functions and services, such as the infinitive demonstrator for piloting electric vehicle charging infrastructures, or the Venteea demonstrator for integrating high wind capacity into a rural network. However, the demonstrators require that the distribution network manager recruit industrial and / or domestic customers who agree to have equipment to test at home. In addition, their operation remains limited by current regulations. Finally, their implementation is often long and costly [17].

In addition to these demonstrators, full-scale experimentation, distribution networks such as Concept Grid, located in Électricité De France (EDF) Lab, allow the testing of new equipment before their installation on the networks of the ERDF distributed. These networks have the advantage of allowing stress tests to be conducted in disturbed conditions, impossible to perform in the context of demonstrators, these involving real customers. However, the reduced size of these networks remains limited [18].

To overcome all these limitations, a third way is simulation. The simulation integrates the three layers that make up Smart Grids: the electrical infrastructure (transformers, lines, loads, sources), the telecommunications infrastructure (mobile networks, PLC) and finally the IS that drive them. Simulators specializing in the simulation of electrical networks (EMTP-RV, Dymola, Power Factory, Eurostag, etc.) as well as telecommunications network simulators (OPNET, NS-3, OMNeT ++, etc.) have already validated the contribution of the simulation in their respective fields

Several types of research have been carried out in recent years many methods that have been used to improve modeling of smart grid, we present here some studies that have been presented in various researches:

Researchers, I. Worighi et al. (2015) [19] have proposed to use the unified modeling language UML as an object oriented tool to describe the concept and reduce the complexity of the system. In order to develop a simple model, they are considered the smart grid as an implementation of several micro-grids which are defined by small electrical systems, these systems are made up of energy sources, including renewable energy sources. To implement and evaluate the proposed model, it is proposed to use a simulation tool, it avoids the deployment of real and expensive infrastructures and reduces the experimental risks. Their goal is to model smart grids with an optimal energy flow, including energy storage systems. The model is used to analyze and study the performance of the system, including the operational and management parts. In this article, the researchers used simulation to implement, test and model their smart grid model, they use UML as a simplified concept that limits ambiguities and provides a visual solution with concepts and analysis tools in a process unified. In this model, objects can be either producers or consumers and the energy can be positive for a producer or negative for a consumer. An object can also be an emitter that transfers energy between objects or any other element contributing to the measurement or the protection of the network.

Researchers, K. Nasraoui et al. (2016) [20] used SysML to provide a simple but powerful description for the modeling of a micro-array system. In fact, they are presented a functional modeling with a use case diagram. Then, a complement to functional modeling with requirements diagram. Then, they are presented behavioral modeling with sequence diagram and structural modeling with BDD and IBD. Finally, a modeling with state machine diagram is presented. First of all, they are presented a hybrid energy system considered as an intelligent micro grid. This system can connect to the macro-grid (main grid) or operate in island mode. The system consists of a solar photovoltaic (PV) panel and a wind turbine (WT) which are used to generate electricity locally. In addition, in order to compensate for the intermittence of renewable energy resources and to optimize the use of this local production, the use of an electricity storage system is taken into account by means of electric batteries.

Researchers, A. Dey et al. (2011) [21] have proposed a smart grid model using Generalized Stochastic Petri Nets GSPN (Generalized Stochastic Petri Nets). The model was used to analyze the constraints and deliverables of the smart electricity grid of the future. The GSPN model of the smart grid, designed in this article, laid the foundation for the functional and performance analysis of the smart grid. The simulation of the model made it possible to analyze how close the behavior of the model is to the behavior of the real smart grid. The average chip distribution was investigated and compared for different numbers of initial random shots. Since then, the designed model has proven to support all the functionalities of the smart grid and incorporate all the technologies used in the smart grid; the model can be used by engineers and smart grid designers for what-if analyzes and all kinds of experiments. The model could have been decomposed into its four phases and the stochastic analysis of the phases could have been performed separately. However, for a correct GSPN analysis valid rates should be assigned to timed transitions and precise weights to immediate transitions. This could only have been done if collaboration with an electricity company had been possible.

Researchers, R. Glaa et al. (2017) [22] have presented in this article a systemic modeling with the OOPP method applied to a photovoltaic generation system. System analysis is presented to create a communication interface between researchers, to analyze and plan the photovoltaic system at different stages, to develop the system in its different stages, to study the installation site and to make the right choice of components. On the other hand, a photovoltaic production chain is described with its different phases in its two modes. Thus, the Matlab simulation made it possible to study the characteristics of a PV module under optimal conditions and under different climatic conditions such as the influence of solar radiation and temperature values on the characteristics of the photovoltaic system. With the smart grid, the field of production becomes very complex, first, the consumer 
participate in the production of "Pro $\neg$ sumers" electricity. It can use its own production, but if there is more production than its consumption, it will be sold or stored in a battery. Second, the one-way direction of the power grid and the data information between the production domain and the operating domain is changed by a two-way direction. It is for this reason that they chose to analyze PV production with the systemic OOPP method.

A. Chabaud (2016) [23] has proposed to use in their research a strategy in order to develop and validate, in simulation, an intelligent approach (predictive or not) and multi-criteria of energy management of a micro-grid, at the scale of an individual home equipped with production and storage systems. This management strategy takes into account the state of the electricity network in order to minimize the impact of local production and electricity consumption. The individual habitat was modeled, as well as the production systems (photovoltaic solar panels and a vertical axis wind turbine) and storage systems (batteries). In addition, several energy and economic criteria are proposed to assess the sizing of these systems and the relevance of the proposed strategy.

R. Seghiri (2016) [24] has presented in their research thesis an objective which makes it possible to provide models, methods and tools allowing to mode, then to simulate an enterprise architecture in order to criticize or validate it. In this context, he proposed a multi-view framework, named Execute EA, to facilitate the modeling of enterprise architectures by automating the analysis of their structures and behaviors through simulation. Execute EA treats each of the business, functional and application views according to three aspects: information, process and objectives. To meet the need for business / IT alignment, he introduced an additional view: the integration view. In this view he presented to model the inter and intra views coherence links. He also used techniques from model-driven engineering as support techniques for modeling and simulating enterprise architecture. Finaly he validates the proposal through a Smart Grid business case relating to the management of a fleet of electric vehicles.

\section{CONCLUSION}

The objective of this paper to present a state of the art on the modeling and optimization of smart grids by integrating random production means such as wind turbines and photovoltaic. This topical issue can improve networkoperating efficiency while respecting imposed constraints, increase efficiency, predict and inform on the impact of renewable energies on networks, which can help prevent problems related to the network. Evolution of these energies and analyze suitable resolutions.

In this context and given the challenges, current electrical networks must absolutely adapt to become smarter, that is to say, integrate new information and communication technologies. More reactive and communicative, they will make it possible to respond to the challenges of integrating electricity production from renewable sources, controlling energy demand, managing peak consumption, developing the use of the electric car and, of course, the opening of the market.

\section{REFERENCES}

[1] X. Chen, H. Dinh, and B. Wang. Cascading failures in smart grid-benefits of distributed generation. IEEE SmartGridComm'10, pages 73-78, 2010.

[2] H. Wertani, J. Ben Salem and M.N. Lakhoua, Analysis and supervision of a smart grid system with a systemic tool, The Electricity Journal, Volume 33, Issue 6, July 2020.

[3] M. Chertkov, F. Pan, and M. G. Stepanov. Predicting failures in power grids: The case of static overloads. IEEE Trans. Smart Grid, 2(1): pages 162-172, 2011

[4] H. Wertani, J. Ben Salem and M.N. Lakhoua, Application of Bond Graph of Renewable Energy Sources in Smart Grids, Journal of Electrical and Electronics Engineering, vol.13, N², 2020.

[5] H. S. Cho, T. Yamazaki, and M. Hahn. Aero: Extraction of user's activities from electric power consumption data. IEEE Trans. Consum. Electron. 56(3): pages 2011-2018, 2010.

[6] M.F. Karoui, H., Aljouni, H. Wertani, M. Jemal and M.N. Lakhoua, Methodology of System Analysis and Monitoring of Wind Power Plant, 6th IEEE International Energy Conference (ENERGYCon), 28 Sept. - 1st Oct. 2020 .

[7] E. H. Clarke. Multipart pricing of public goods. Public Choice, 11(1): pages 17-33, 1971

[8] K. Clement, E. Haesen, and J. Driesen. Coordinated charging of multiple plug-in hybrid electric vehicles in residential distribution grids. IEEE PSCE'09, pages 1-7.

[9] K. Clement-Nyns, E. Haesen, and J. Driesen. The impact of charging plugin hybrid electric vehicles on a residential distribution grid. IEEE Trans. Power Syst., 25(1): pages 371-380, 2010.

[10] F. M. Cleveland. Cyber security issues for advanced metering infrastructure (AMI). IEEE Power and Energy Society General Meeting: Conversion and Delivery of Electrical Energy in the 21st Century, pages 1-5, 2008.

[11] D. Coll-Mayor, M. Paget, and E. Lightner. Future intelligent power grids: Analysis of the vision in the European Union and the United States. Energy Policy, pages 2453-2465, 2007.

[12] C. M. Colson and M. H. Nehrir. A review of challenges to real-time power management of microgrids. IEEE Power \& Energy Society General Meeting, pages 1-8, 2009.

[13] A. J. Conejo, J. M. Morales, and L. Baringo. Real-time demand response model. IEEE Trans. Smart Grid, 1(3): pages 236-242, 2010.

[14] F. J. C. Corripio, J. A. C. Arrabal, L. D. del R'10, and J. T. E. Munoz. Analysis of the cyclic short-term variation of indoor power line channels. IEEE J. Sel. Areas Commun, 24(7): pages 1327-1338, 2006.

[15] H. Wertani and M.N. Lakhoua, Overview of Smart Grids Architecture and Design, SmartNets2018, Hammamet Tunisia, November 15-17, 2018.

[16] G. D'an and H. Sandberg. Stealth attacks and protection schemes for state estimators in power systems. IEEE SmartGridComm'10, pages 214-219, 2010.

[17] J. De La Ree, V. Centeno, J. S. Thorp, and A. G. Phadke. Synchronized phasor measurement applications in power systems. IEEE Trans. Smart Grid, 1(1): pages 20-27, 2010.

[18] U. D. Deep, B. R. Petersen, and J. Meng. A smart microcontroller based iridium satellite-communication architecture for a remote renewable energy source. IEEE Trans. Power Del., 24(4): pages 1869-1875, 2009.

[19] I. Woroghi A. Maach and A. Hafid. Modeling a Smart Grid using Objects Interaction. Proceedings of the IEEE power and energy society general meeting, 2015.

[20] K. Nasraoui, M.N. Lakhoua and L. El Amraoui. Analysis and Modeling of a Wind Power Systembased on SysML. Proceedings of the International Conference on Recent Advances in Electrical Systems, Tunisia, 2016.

[21] A. Dey N. Chaki and S. Sanyal. Modeling Smart Grid using Generalized Stochastic Petri Net. Renew. Sustain. Energy Rev., Vol. 43, page. 51-64, 2011.

[22] R. Glaa, N. Jeddi, M.N. Lakhoua and L. El Amraoui. Application of system modeling and simulation of the photovoltaic production. Advances in Science and Technology Research Journal, Vol.11, Issue 3, 2017.

[23] A. Chabaud. Micro-réseau intelligent pour la gestion des ressources énergétiques. University de perpignan via domitia, 2014.

[24] R. Seghiri. Modélisation et simulation d'une architecture d'entreprise Application aux Smart Grids. Université paris-saclay préparée à centralesupelec, 2016.

\section{Creative Commons Attribution License 4.0 (Attribution 4.0 International, CC BY 4.0)}

This article is published under the terms of the Creative Commons Attribution License 4.0 https://creativecommons.org/licenses/by/4.0/deed.en_US 